\title{
Identification and analysis of hub genes and networks related to hypoxia preconditioning in mice (No 035215)
}

\author{
Haiting Cheng ${ }^{1,3, *}$, Can Cui ${ }^{1, *}$, Shousi Lu ${ }^{2, *}$, Binbin $\mathrm{Xia}^{1}$, Xiaorong $\mathrm{Li}^{1}$, Pinxiang $\mathrm{Xu}^{1}$ \\ and Ming Xue ${ }^{1}$ \\ ${ }^{1}$ Department of Pharmacology, Beijing Laboratory for Biomedical Detection Technology and Instrument, School of Basic \\ Medical Sciences, Capital Medical University, Beijing 100069, China \\ ${ }^{2}$ China Rehabilitation Research Center, Beijing 100068, China \\ ${ }^{3}$ Department of Pharmacy, Beijing Stomatological Hospital, Capital Medical University, Beijing 100050, China \\ *These authors contributed equally to this work \\ Correspondence to: Ming Xue, email: xuem@ccmu.edu.cn
}

Keywords: hypoxia preconditioning; hub genes; microarray; network analyses

Received: July 07, $2017 \quad$ Accepted: October 28, $2017 \quad$ Published: December 21, 2017

Copyright: Cheng et al. This is an open-access article distributed under the terms of the Creative Commons Attribution License 3.0 (CC BY 3.0), which permits unrestricted use, distribution, and reproduction in any medium, provided the original author and source are credited.

\section{ABSTRACT}

Hypoxia preconditioning is an effective strategy of intrinsic cell protection. An acute repetitive hypoxic mice model was developed. High-throughput microarray analysis was performed to explore the integrative alterations of gene expression in repetitive hypoxic mice. Data obtained was analyzed via multiple bioinformatics approaches to identify the hub genes, pathways and biological processes related to hypoxia preconditioning. The current study, for the first time, provides insights into the gene expression profiles in repetitive hypoxic mice. It was found that a total of $\mathbf{1 1 7 5}$ genes expressed differentially between the hypoxic mice and normal mice. Overall, 113 significantly up-regulated and 138 significantly down-regulated functions were identified from the differentially expressed genes in repetitive hypoxic brains. Among them, at least fourteen of these genes were very associated with hypoxia preconditioning. The change trends of these genes were validated by reversetranscription polymerase chain reaction and were found to be consistent with the microarray data. Combined the results of pathway and gene co-expression networks, we defined Plcb1, Cacna2d1, Atp2b4, Grin2a, Grin2b and Glra1 as the main hub genes tightly related with hypoxia preconditioning. The differential functions mainly included the mitogen-activated protein kinase pathway and ion or neurotransmitter transport. The multiple reactions in cell could be initiated by activating MAPK pathway to prevent hypoxia damage. PIcb1 was an important and hub gene and node in the hypoxia preconditioning signal networks. The findings in the hub genes and integrated gene networks provide very useful information for further exploring the molecular mechanisms of hypoxia preconditioning.

\section{INTRODUCTION}

The maintenance of oxygen homeostasis in cells, tissues, organs and organisms is a complex process of integration and regulation, which is primarily dominated via changes in gene expression. Oxygen deprivation (hypoxia) is a great challenge in some conditions such as high plateau, deep sea, and aviation [1]. Hypoxia might be associated with many pathophysiological processes and diseases such as stroke, asthma, emphysema, angina pectoris, myocardial infarction and tumor [2]. Oxygen is indispensable for all aerobic life as the final electron acceptor in the cellular respiration chains [3]. Successful adaptation to hypoxia involves various changes in gene programs including cellular differentiation, metabolism, growth, aging and death. Since complicated genes and pathways are involved in the regulation of oxygen homeostasis, the molecular mechanisms that underpin 
these networks are not yet fully understood. Hypoxia preconditioning (HPC) is an effective strategy of intrinsic cell protection that developed during biological evolution [4]. HPC is triggered by the repetitive exposure of organisms, organs, tissues and cells to hypoxia, resulting in an increased acclimatization to subsequent exposure to severe hypoxia. The results indicated that the survival time of HPC mice was significantly longer than that of the normal mice, suggesting that HPC had a markedly protective effect against hypoxia damage [5-8]. Although the protective effect clearly exists and some investigations have been performed, the protective mechanisms of HPC still remain unclear, especially at molecular level of the genes involved.

High-throughput microarray analysis is an effective approach to profile gene expression and has been successfully applied to investigate crucial genes related to HPC $[9,10]$. Because of the high sensitivity to hypoxia, the brain tissue has been used to identify the important genes related to HPC by microarray gene-chip and gene network analyses. The gene network analysis is a powerful tool and has been used to investigate the detailed interactions among genes $[11,12]$. In the current study, the changes in gene expression levels were observed between the experimental group and control group by multiple sample analysis. The multiple bioinformatics analysis approaches have been used to construct the gene networks of HPC, and the hub genes in these networks have been identified. The expression analyses of entire genome combined with gene network analyses are expected to reveal the protective mechanisms for HPC. Here, the genes in the brain tissue of HPC group and control group were analyzed using the Affymetrix Gene 1.0 Array [11]. In addition, Real-time reverse-transcription polymerase chain reaction (RT-PCR) was used to validate the differential expression of genes identified by microarray analysis. The microarray analysis was used to detect the differential gene expression of mouse brain in acute repetitive hypoxia conditions. Multiple bioinformatics methods were used to reveal the molecular mechanism associated with HPC.

\section{RESULTS}

\section{Mouse model of HPC}

The mice exposed to hypoxic condition for six times (H6) were adopted as the HPC animal model. The mice of repeated six times sham-HPC were employed as the control group. The tolerance duration of the HPC mice were recorded when the asthmoid respiration of hypoxic mice just appeared. It was noted that the tolerance duration of mice to hypoxia was significantly prolonged as the number of exposure increased. The mean tolerance time of H6 mice was up to 6.8 times longer than that of the mice on their first exposure to hypoxia even though the tolerance times had some animal differences [7, 8]. A linear relationship between the tolerance times and the number of times exposed was observed in the HPC mice $\left(\mathrm{y}=16.471 \mathrm{x}+0.888, R^{2}=0.9882\right)$, suggesting a positive correlation between the exposure times and the tolerance duration to some extent. But there was some individual variance in the HPC mice at the different hypoxic exposure time owing the biological differences.

\section{Screening and analysis of differential gene}

The gene expression profiles in the H6 mice and the sham-HPC mice were examined using an Affymetrix microarray. The random variance model (RVM) $t$-test was applied to screen the differentially expressed genes from these two groups, which was suitable for cases of small samples $[13,14]$. Based on the significant analysis and the false discovery rate (FDR), the differentially expressed genes were selected at a cutoff threshold of $p<0.05$ and FDR $<0.05$. Compared with the sham-HPC mice, a total of 1175 genes of H6 mice showed significant difference in their expression levels. Among these genes, 460 genes were up-regulated in the H6 mice with a maximum fold change of 47.26 times. 715 genes were down-regulated genes in the H6 mice with the fold change of 20 times. A volcano plot of all the genes in the microarray is shown in Figure 1 . The top 20 differentially expressed genes in the H6 mice are listed in Table 1.

\section{GO analysis based on differential genes}

The Fisher's exact test and $\chi^{2}$ test were used to classify the GO categories, and the FDR was used to calculate and adjust the $p$-value [15]. A low FDR indicates that the error is small in judging the $p$-value. The $p$-value was computed for the GO categories for the differential genes. Enrichment was used to measure the significance of assigned GO functions. The analysis revealed 113 upregulated and 138 down-regulated functions that were significantly enriched among the differentially expressed genes (see Supplementary Table 1 and Supplementary Table 2). The significantly enriched functions of upregulated genes included ion transport, neurotransmitter transport, synaptic transmission, signal transduction, and cranial nerve development. The significantly enriched functions of down-regulated genes included calcium and potassium ion transport, nervous system and brain development, and neuron migration and neuronal differentiation.

All the significantly enriched GO terms were assembled into a GO map (see Figure 2) to help to visualize the interactive networks. The GO map can systemically construct the interaction networks of significant GO terms [13]. The nodes in the networks represent the functions of differential genes, and the lines represent the relationship between the functions. Twenty-one sub-networks were revealed including 
signal transduction, synaptic transmission, brain development, neuron differentiation, axonogenesis and cell proliferation. The interaction networks in the GO map suggested that HPC may trigger a series of signal transduction events involving GTPase-mediated signal transduction and G-protein signaling pathways. The cell proliferation, intermediating filament, and neurotransmitter transport functions were up-regulated in the H6 mice brains, while the vasodilatation, calcium ion transport, and blood pressure functions were downregulated in the $\mathrm{H} 6$ brains.

\section{Pathway analysis based on the significant differential genes}

The main pathways linked to the significant differential genes were assigned based on the pathway maps of KEGG, Biocarta and Reactome. Nineteen of the up-regulated signaling pathways are listed in Supplementary Table 3, including neuro-active ligandreceptor interaction, mitogen-activated protein kinase (MAPK) signaling pathway, calcium signaling pathway, inositol phosphate and ether lipid metabolic pathways
[15]. The relationships among these pathways were built using the PathNet, summarized in Figure 3. The Path-Network was the interactive network of significant pathways from the differential expression genes, which was constructed according to the interaction pathways of KEGG database. In these pathway networks, MAPK signaling pathway had the greatest degree; it existed at the central position of Path-Network by mediating the cascade reactions. MAPK is the serine-threonine kinase that regulates multiple cellular functions such as mitogens, inflammatory cytokines, gene expression and cell survival or apoptosis, etc. MAPK is also a key component for extra-cellular stimuli. During HPC process, the multiple molecular reactions in cells could be initiated by activating MAPK pathway to prevent hypoxia damage [16].

\section{Signal network analysis based on differential genes}

Signal networks of gene interactions were constructed to reveal the relationships among the significant differential genes, and to map the upstream and downstream of target genes (see Figure 4). When

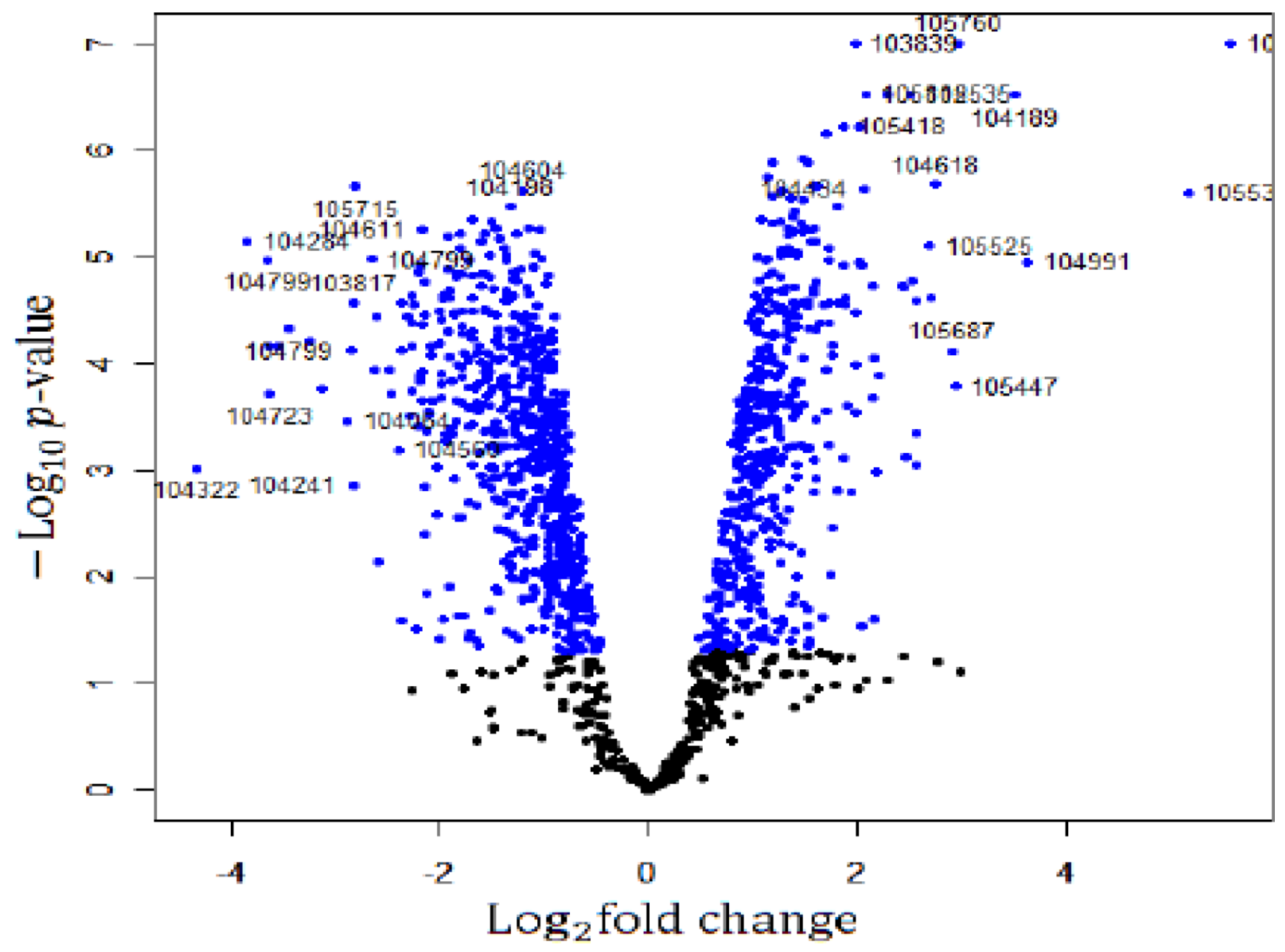

Figure 1: A volcano plot of the genes in microarray. The $\log ^{2}$ fold changes and their corresponding $-\log ^{10} p$-value of all genes were taken for construction of the volcano plot in the microarray. The genes with $p<0.05$ are depicted in blue dots. All other genes that were not found to be significant altered are in black dots in this array. 
there was evidence that two genes interacted with each other, an interaction edge was assigned between the two genes. To investigate the entire signal networks, the most important nodes were identified computationally. The connectivity was defined to measure how closely a target gene correlated with other genes in this network. The degree was estimated according to the number of genes correlated with the target gene. The characteristics of these genes were described by the betweenness centrality of nodes, which reflected the importance of a node in a graph relative to other nodes. It was noted that Plcb1, encoded phospholipase that had crucial roles in lipid metabolism, was significantly down-regulated in the H6 mice. The interaction networks of differential genes

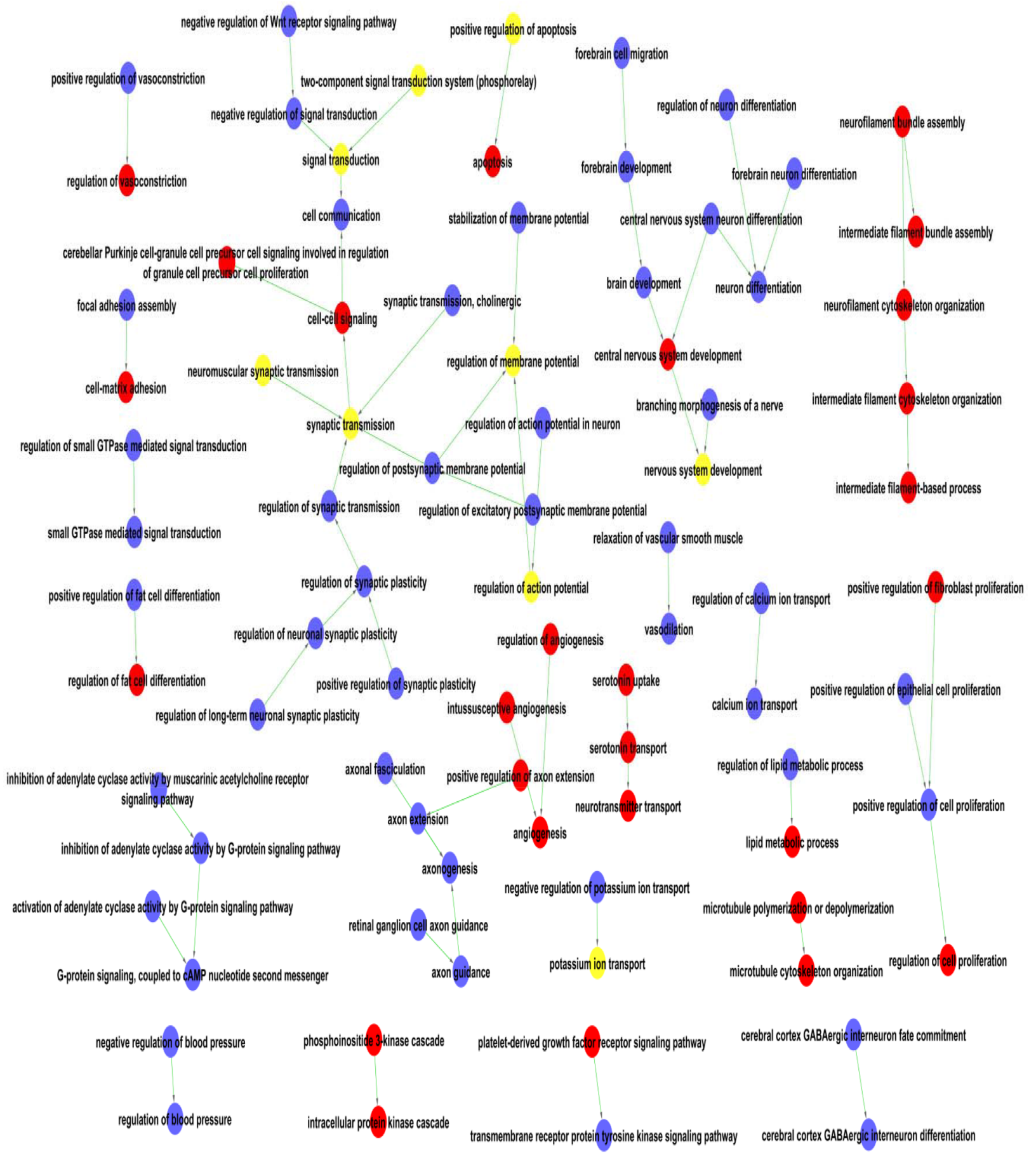

Figure 2: The function networks of the differentially expressed genes by GO terms. One node represents one GO term and function of one differential gene. The red nodes represent the up-regulated genes, the blue nodes represent the down-regulated gene and the yellow nodes mean both up and down regulated gene. The lines represent the relationship of the functions, with arrow from the lower ranking Go term pointing towards to the higher one. 
Table 1: The top 20 differentially expressed genes in HPC mice

\begin{tabular}{|c|c|c|c|c|c|c|}
\hline $\begin{array}{l}\text { Gene } \\
\text { Symbol }\end{array}$ & $p$-value & $\begin{array}{l}\text { FDR } \\
\text { value }\end{array}$ & $\begin{array}{l}\text { Geom mean of intensities } \\
\text { in experimental group }\end{array}$ & $\begin{array}{c}\text { Geom mean of } \\
\text { intensities in control } \\
\text { group }\end{array}$ & $\begin{array}{l}\text { Fold } \\
\text { change }\end{array}$ & Trend \\
\hline Glral & $8.157 \mathrm{E}-12$ & $1.813 \mathrm{E}-11$ & 2650.31 & 56.08 & 47.26 & up \\
\hline Foxfla & $3.199 \mathrm{E}-11$ & $3.555 \mathrm{E}-11$ & 551.13 & 70.9 & 7.77 & up \\
\hline Nefh & $6.781 \mathrm{E}-11$ & $5.023 \mathrm{E}-11$ & 1345.14 & 343.73 & 3.91 & up \\
\hline Tрpp3 & 0.0000003 & $4.896 \mathrm{E}-05$ & 1202.14 & 286.92 & 4.19 & up \\
\hline Ankrd55 & 0.0000003 & $4.896 \mathrm{E}-05$ & 368.15 & 76.36 & 4.82 & up \\
\hline Slc17a6 & 0.0000003 & $4.896 \mathrm{E}-05$ & 976.2 & 174.12 & 5.61 & up \\
\hline Sncg & 0.0000003 & $4.896 \mathrm{E}-05$ & 984.48 & 87.66 & 11.23 & up \\
\hline Vampl & 0.0000006 & $7.63 \mathrm{E}-05$ & 3440.73 & 956.74 & 3.6 & up \\
\hline Foxfla & 0.0000006 & 7.63E-05 & 380.63 & 94.12 & 4.04 & up \\
\hline Adamts 9 & 0.0000012 & 0.0001141 & 156.57 & 56.26 & 2.78 & up \\
\hline Dennd3 & 0.0000013 & 0.0001141 & 155.66 & 69.33 & 2.25 & up \\
\hline Apold1 & 0.0000013 & 0.0001141 & 239.55 & 84.38 & 2.84 & up \\
\hline Dock5 & 0.0000018 & 0.0001296 & 180.49 & 82.61 & 2.18 & up \\
\hline Prune2 & 0.0000021 & 0.0001296 & 205.25 & 30.72 & 6.68 & up \\
\hline Asah2 & 0.0000022 & 0.0001296 & 470.21 & 158.82 & 2.96 & up \\
\hline$C d 38$ & 0.0000022 & 0.0001296 & 400.77 & 131.11 & 3.06 & up \\
\hline Cdkn1a & 0.0000023 & 0.0001296 & 910.32 & 219.95 & 4.14 & up \\
\hline Spnb3 & 0.0000024 & 0.0001296 & 341.48 & 785.22 & 0.43 & down \\
\hline Ahnak2 & 0.0000024 & 0.0001296 & 201.92 & 84.16 & 2.4 & up \\
\hline Slc6a5 & 0.0000025 & 0.0001296 & 2625.3 & 74.1 & 35.43 & up \\
\hline
\end{tabular}

Table 2: The interaction networks of hub genes in HPC mice brain

\begin{tabular}{|c|c|c|c|c|c|c|}
\hline $\begin{array}{l}\text { Gene } \\
\text { symbol }\end{array}$ & Description & $\begin{array}{l}\text { Betweenness } \\
\text { centrality }\end{array}$ & Degree & Indegree & Outdegree & Style \\
\hline Plcb1 & $\begin{array}{l}\text { Mus musculus phospholipase } \mathrm{C} \text {, beta } 1 \text { (Plcb1), } \\
\text { transcript variant } 2 \text {, mRNA. }\end{array}$ & 0.996131 & 17 & 16 & 16 & down \\
\hline Pip5k1a & $\begin{array}{l}\text { Mus musculus phosphatidylinositol-4-phosphate } \\
\text { 5-kinase, type } 1 \text { alpha (Pip5k1a), mRNA. }\end{array}$ & 0.7864583 & 6 & 5 & 6 & down \\
\hline Itga5 & $\begin{array}{l}\text { Mus musculus integrin alpha } 5 \text { (fibronectin } \\
\text { receptor alpha) (Itga5), mRNA. }\end{array}$ & 0.3208333 & 5 & 5 & 3 & down \\
\hline Actn1 & Mus musculus actinin, alpha 1 (Actn1), mRNA. & 0.271875 & 3 & 3 & 3 & down \\
\hline Actn2 & Mus musculus actinin alpha 2 (Actn2), mRNA. & 0.271875 & 3 & 3 & 3 & down \\
\hline Prkcb & $\begin{array}{l}\text { Mus musculus protein kinase } \mathrm{C} \text {, beta (Prkcb), } \\
\text { mRNA. }\end{array}$ & 0.2330357 & 9 & 4 & 8 & down \\
\hline Plcd4 & $\begin{array}{l}\text { Mus musculus phospholipase C, delta } 4 \text { (Plcd } 4 \text { ), } \\
\text { transcript variant } 1 \text {, mRNA. }\end{array}$ & 0.219122 & 11 & 11 & 11 & up \\
\hline Plce1 & $\begin{array}{l}\text { Mus musculus phospholipase C, epsilon } 1 \\
\text { (Plce1), mRNA. }\end{array}$ & 0.219122 & 11 & 11 & 11 & up \\
\hline Rasgrp1 & $\begin{array}{l}\text { Mus musculus RAS guanyl releasing protein } 1 \\
\text { (Rasgrp1), mRNA. }\end{array}$ & 0.2 & 9 & 8 & 9 & down \\
\hline Prkca & $\begin{array}{l}\text { Mus musculus protein kinase } \mathrm{C} \text {, alpha (Prkca), } \\
\text { mRNA. }\end{array}$ & 0.1607143 & 8 & 3 & 8 & down \\
\hline
\end{tabular}


demonstrated that $P l c b 1$ displayed the largest betweenness centrality, implying that this gene was mostly involved in interactions with other genes in HPC (showed in Table 2). $P l c b 1$ showed the highest activity and might perform as an intermediary in the networks, suggesting that $P l c b 1$ was a hub gene and a key node in these signal networks.

\section{Gene co-expression networks based on GO and pathway analyses}

On basis of normalized signal intensities for these differential expression genes, the co-expression networks were constructed with an aim to identify the core regulatory genes $[17,18]$. The degree centrality, as a simplest and most important index, was defined to describe the number of links that one node connecting to the other in the network. In addition, the k-cores were introduced as a method to simplify the analysis of graph topology. The k-core presented as a sub-network where the nodes were connected to others.
The gene co-expression networks for the H6 and sham-HPC mice were also constructed based on the gene expression data (seen in Figure 5 and Figure 6). The dominated genes were screened and identified based on the co-expression network and status changes. The co-expression changes of these key genes reflected the differences of brain samples between the $\mathrm{H} 6$ mice and sham-HPC mice.

\section{Amplification and verification of differential expression genes by RT-PCR}

Quantitative real-time RT-PCR was used to validate the reliability of microarray results. Fourteen hub genes with more than 2-fold differential expression in the networks were studied. The gene expression levels were quantified relative to the expression level of $\beta$-actin by the $2^{-\Delta \Delta \mathrm{Ct}}$ method [19]. The RT-PCR results suggested that ten differentially expressed genes (Cacna2d1, Grin2a, Npy1r, Mef2c, Epha4, Rxfp1, Chrm3, Pdela, Atp2b4 and

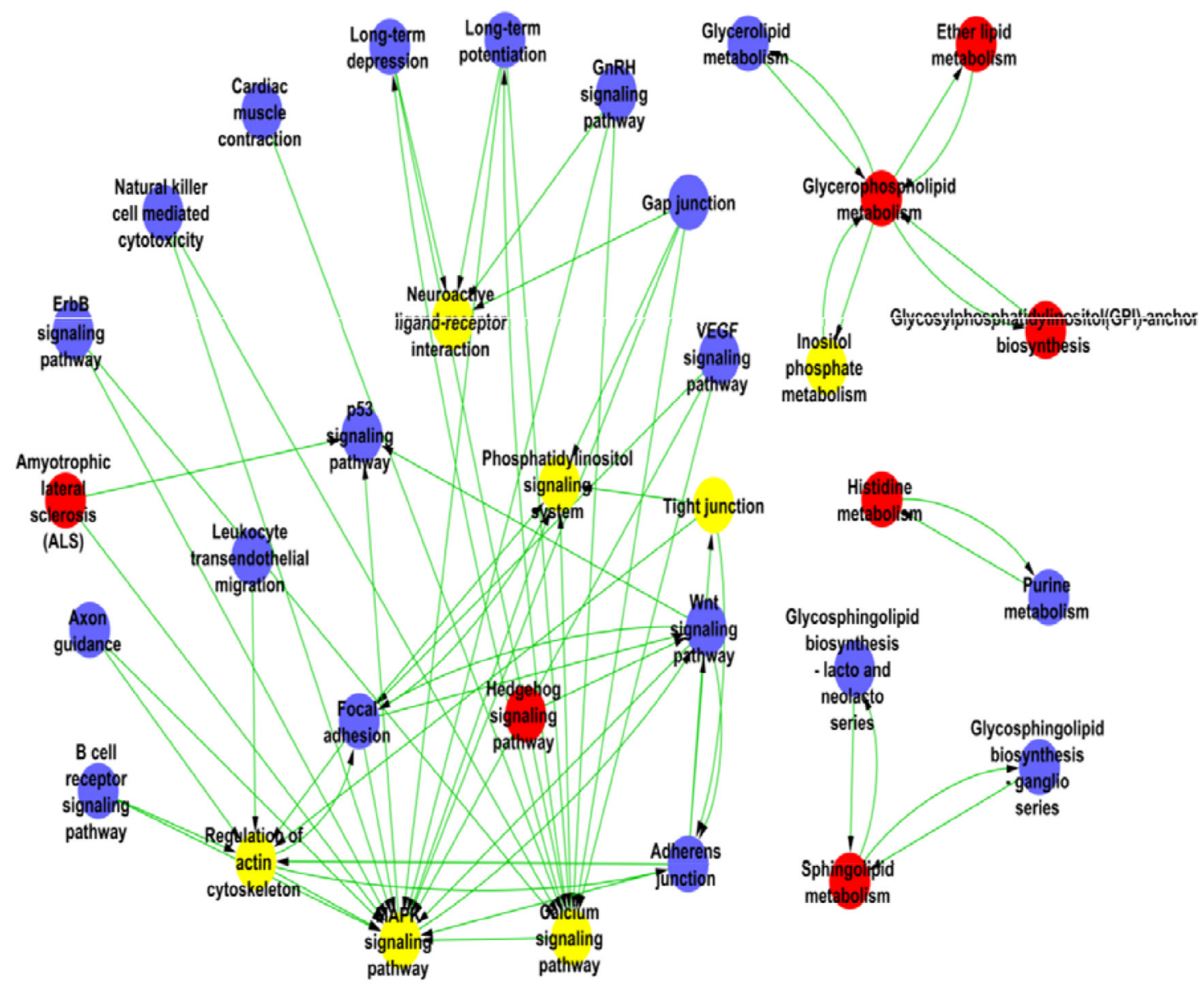

Figure 3: The pathway network of the differentially expressed genes in HPC mice. The nodes represent the pathways and the lines represent the relationship between the pathways. The red nodes mean up-regulated pathways; the blue nodes mean down-regulated pathways and the yellow mean both up and down regulated pathways. 
Grin $2 b$ ) were significantly down-regulated in the H6 mice brains compared with those in the sham-HPC mice. Four genes (Glral, Idil, Fgfl and Cda) were significantly upregulated in the H6 mice (shown in Figure 7). The findings from the RT-PCR experiments, including the variation trends and expression levels of these fourteen genes, were in line with that from the microarray analysis.

Based on our data, the gene networks were constructed for the major genes related to HPC mice. The results showed that: (1) there were marked differences in the gene expression profiles between the HPC mice and control group; (2) the hub genes such as Plcbl was crucial in HPC process; and (3) the microarray and gene network analyses were very powerful tools to identify the HPC hub gene.

\section{DISCUSSION}

The ability to sense oxygen levels and maintain oxygen homeostasis is crucial for cell survival. The hypoxic-sensitive regulation of gene expression for oxygen status can be converted into appropriate cellular responses. Although there are some core transcriptional pathways in cells, the signaling cascades can be modified to allow the diversity and specificity in transcriptional output. Pathophysiological conditions and diseases such as cardiovascular disease, stroke and cancer often lead to a significant decrease in oxygen supply to cells. Hypoxia can also induce the significant metabolic changes. Oxygen homeostasis in organisms is a complex process of integration and regulation via the hub gene and protein

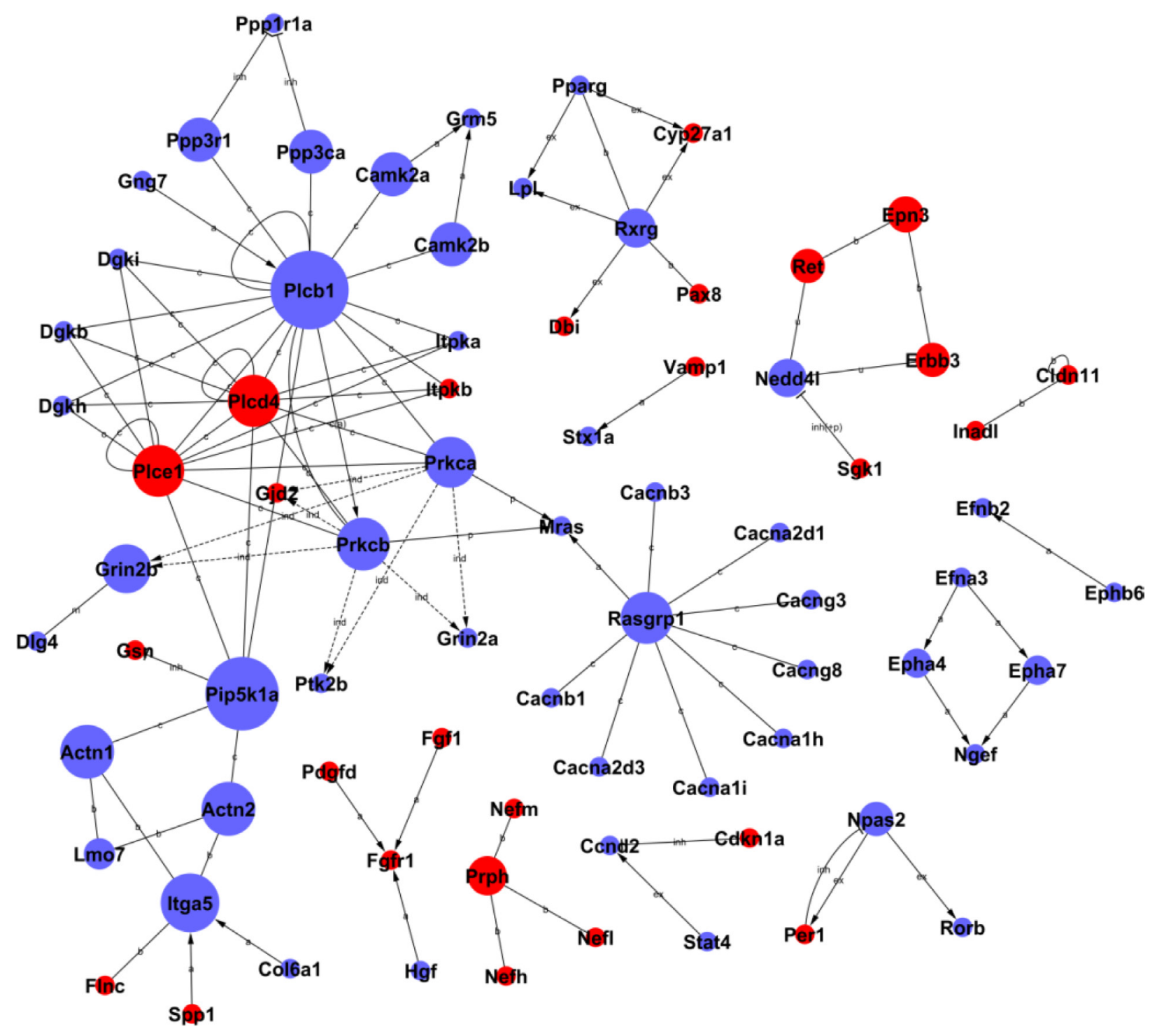

Figure 4: The interaction networks of differentially expressed genes in HPC mice. The nodes represent the genes, the red nodes mean the up-regulated genes and the blue nodes mean the down-regulated genes. The edges indicate the interaction between the genes. The arrows show the action direction. The size of nodes means the level of expressed degree. All the nodes were marked with k-core values. The genes with higher k-core values are more centralized in the network and have a stronger capacity of modulating adjacent genes. 
expression. Successful adaptation to hypoxia involves changes in the gene programs that modulate cellular metabolism for substances and energy [20]. Thus, the gene networks that govern oxygen homeostasis are of great significance for investigation into the molecular mechanisms of hypoxia and HPC. The microarray and gene network analyses are effective approaches to identify HPC-related genes and reveal the molecular mechanisms of HPC [21]. Generally, high-throughput data have the features of high variability, low reproducibility and nonspecific noise. The subgroups of genes within the dataset may be associated with a generalized response to a given stimulus [22]. This effect can be ameliorated using comprehensive bioinformatics approaches including gene analysis, GO analysis, gene network and pathway analysis to enrich the relevant and responsive genes for HPC.

In our study, the oxygen content of mice exposed to hypoxia was determined via the $\mathrm{pHOxCO}-\mathrm{Oximeter}$ methods [5]. The results indicated a marked relationship between the number of hypoxia exposures and the remained oxygen concentration or oxygen content. The values of oxygen content, oxygen saturation and oxyhemoglobin were markedly decreased in the HPC groups. Significant differences were evident between these groups $(p<0.05$ or $p<0.01)$, indicating that the oxygen content was markedly decreased in successive HPC groups. Our data indicated that the HPC model was successful and the brain samples could be used to the hypoxic experiments $[7,8]$.

The approaches provide a comprehensive overview for thousands of HPC related genes, and enormously expand our view of molecular and metabolic changes in hypoxia and HPC responses. The two most important gene discovery techniques available to gene hunter are the DNA microarray screening and cDNA library screening. We have used them to successfully analyze the diverse animal models of hypoxia and HPC. To comprehensively understand the processes of HPC in mice, the whole brain was subjected to HPC to identify the differentially expressed genes. In our study, the differentially expressed genes in HPC brains were found to be involved in ion transport, neurotransmitter transport, synapse transduction, neuropeptide signal conduction, and cranial nerve development. Bioinformatics combined with gene network analysis has been effectively used to identify the hub genes that may be as therapeutic targets of hypoxia related diseases [21].

In our study, 1175 HPC-related differentially expressed genes have been identified. By filtering significant differential genes and building co-expression networks, a variety of methods are available to provide a more systemic and intuitive insight into the HPC process [23]. Of the 1175 differentially expressed genes, 113 were up-regulated and 138 were down-regulated in the HPC mice brains compared with those the sham-HPC controls (Supplementary Table 1 and Supplementary Table 2).
The GO analysis of 1175 differentially expressed genes suggested that the cellular signaling processes, especially, the electron transport rate of the respiratory chains, were the most important. The GO terms for the response of brain cells to hypoxic stimuli were confirmed by the GO map analysis. The high correlation between the HPC and the constructed gene networks reflected the high sensitivity of differentially expressed genes Plcb1, Cacna2d1, Atp2b4, Grin2a, Grin2b, and Glra1 to HPC. Meantime, the pathway network showed that these genes also participated in hub pathways. Combined the results of pathway network and gene co-expression network (see Supplementary Table 3 and Supplementary Table 4), we defined Plcb1, Cacna2d1, Atp2b4, Grin2a, Grin2b and Glral as the main hub genes tightly associated with HPC.

Our results indicated that Plcbl had the largest betweenness centrality and more interactions with other differential genes, suggesting that Plcbl is a main key gene in the HPC networks. Plcbl participated in eleven significant down-regulated pathways, including calcium signaling pathway, Wnt signaling pathway, vascular smooth muscle contraction and so forth. Plcbl encodes a phospholipase that belongs to the PLC family [24]. The main function of Plcb1 is to produce the second messengers such as inositol triphosphate $\left(\mathrm{IP}_{3}\right)$ and diacylglycerol (DAG). After binding to the receptors on endoplasmic reticulum, $\mathrm{IP}_{3}$ can open calcium ion channels in the membrane, which allows calcium ions to cross into the cytoplasm [25]. Plcb1 was markedly down-regulated in the H6 mice brains, indicating that calcium levels in the cytoplasm may decline to avoid calcium overload and prevent hypoxia damage. Interestingly, the isogeny both Plcd4 and Plcel were markedly up-regulated in the H6 mice, inferring that these two genes also play an important role in HPC. In addition, Pip5kla encoded phosphatidylinositol-4-phosphate 5-kinase type 1 alpha, markedly down-regulated and had the larger betweenness centrality and interactions, suggesting that Pip5kla was a key gene in the HPC networks.

Cacna2d1 and Cacna2d3 encoded the subunits $\alpha 2 \delta 1$ and $\alpha 2 \delta 3$, is a protein complex in voltagedependent L-type calcium channel that maintains intracellular calcium level [26, 27]. Cacna2d1 was down-regulated by at least two fold in the HPC mice brains. The pathway analyses indicated that Cacna2d1 was responsible for ion transport in the MAPK pathway. MAPK is a serine-threonine kinase that regulates multiple cellular functions such as mitogens, proinflammatory cytokines, gene expression, and cell survival or apoptosis. Further, MAPK is a major component in a series of cascade reactions and an important factor in extra-cellular stimuli. During the HPC, these reactions in the cells could be initiated by activating the MAPK pathway to prevent hypoxia damage [28]. In addition, the coexpression network showed that the expression levels 
of Cacna2d1 had markedly difference between the H6 mice and sham-HPC mice. In the sham-HPC mice, Cacna2d1 expression was positively correlated with the expression of the gene Dusp1, Gabre and Fos, and negatively correlated with Idil. While in the H6 mice, Cacna2dl expression was positively correlated with the gene Atp2b4, Ppp1r1a, Cacna2d3 and Grin2a, and negatively correlated with $T p h 2$. The co-expression results indicated that the expression levels of both Cacna2d1 and Cacna2d3 decreased in the HPC. These findings suggested that inhibition of calcium influx by down-regulation of Cacna2d1 may be one of the protection mechanisms of HPC.

The gene Atp2b4, encoded a membrane calcium transporter, i.e., adenosine triphosphatase (ATPase) [29], was down-regulated 2.1 times and was co-expressed with Cacna2d1 in the $\mathrm{H} 6$ mice brains. The GO analysis showed that the main function of Atp24 was to transport calcium. The pathway analysis indicated that Atp $2 b 4$ also participated in the calcium signaling pathway. The protein encoded by Atp $2 b 4$ belongs to the family of P-type primary ion transport ATPases. The main function of the enzyme is to remove the bivalent calcium ions from eukaryotic cell against high concentration gradients, and plays a crucial role in maintaining intracellular calcium homeostasis. The ATPase uses an energy-consuming process to promote calcium outflow or storage in organelles, resulted in decline of intracellular calcium [30]. The down-regulation of Atp $2 b 4$ in HPC mice may lead to a decrease in the ATPase in cell membrane, implying that calcium may be

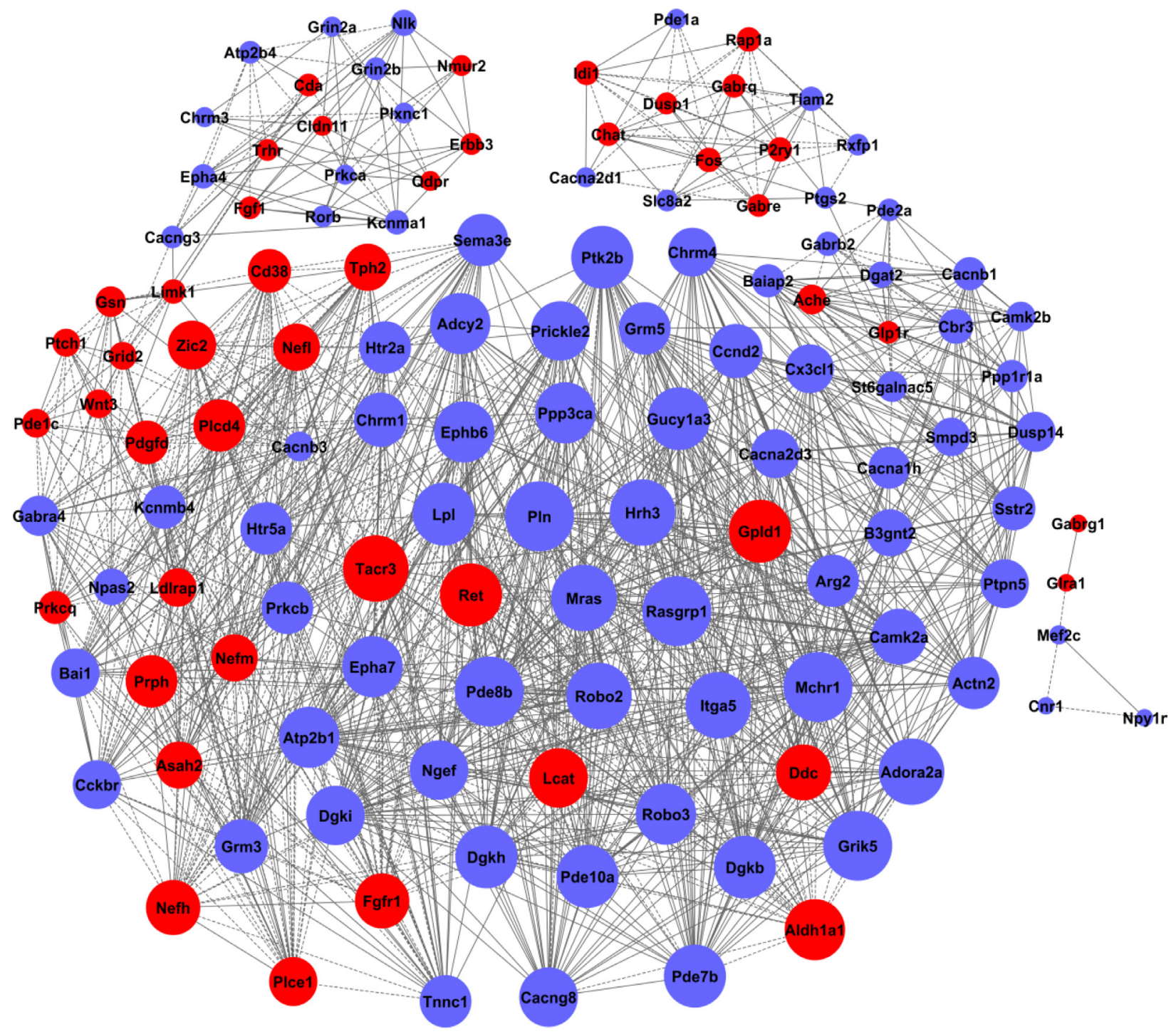

Figure 5: The co-expression network of genes formed from the control group. The genes contained in the significant GO terms were analyzed and identified by the gene co-expression network with the k-core algorithm. The node represents the gene, the red nodes mean the up-regulated genes, the blue nodes mean the down-regulated, and all the nodes were marked with the k-core values. The genes with higher k-core values are more centralized in the network and have a stronger capacity of modulating adjacent genes. The line represents the regulatory relationship, the solid line means the positive regulation and the dotted line means the negative regulation. 
transported by low energy-consuming processes related to Cacna2d1 and Cacna2d3. Thus, the HPC tissues could use an endogenous mechanism to reduce the energy consumption and contribute to the protective effect of HPC.

Grin $2 a$ and Grin $2 b$ were also significant differential genes that had markedly different co-expression levels between the HPC and the control group [31]. The pathway network showed that these two genes involved in calcium signaling pathway, neuroactive ligand-receptor interaction and long-term potentiation. Grin $2 a$ and Grin $2 b$ encoded the ionotropic glutamate receptor N-methyl-D-aspartate
NMDA2A and NMDA2B subtypes, respectively. This receptor was a member of ionotropic glutamate receptor and involved in long-term potentiation. This receptor was linked to the ion channel that $\mathrm{Mg}^{2+}$ can block $\mathrm{Ca}^{2+}$ influx into the cell via the NMDA channel in resting state. When the NMDA receptors activated, the membrane channels open, $\mathrm{Mg}^{2+}$ released from the cell and $\mathrm{Ca}^{2+}$ influxes into the cell, resulting in $\mathrm{Ca}^{2+}$ overload and cellular damage. The co-expression network results showed that Grin $2 a$ and Grin $2 b$ were both down-regulated in the HPC mice, suggesting that the levels of NMDA2A and NMDA2B may decrease in the HPC mice. Our study indicated that

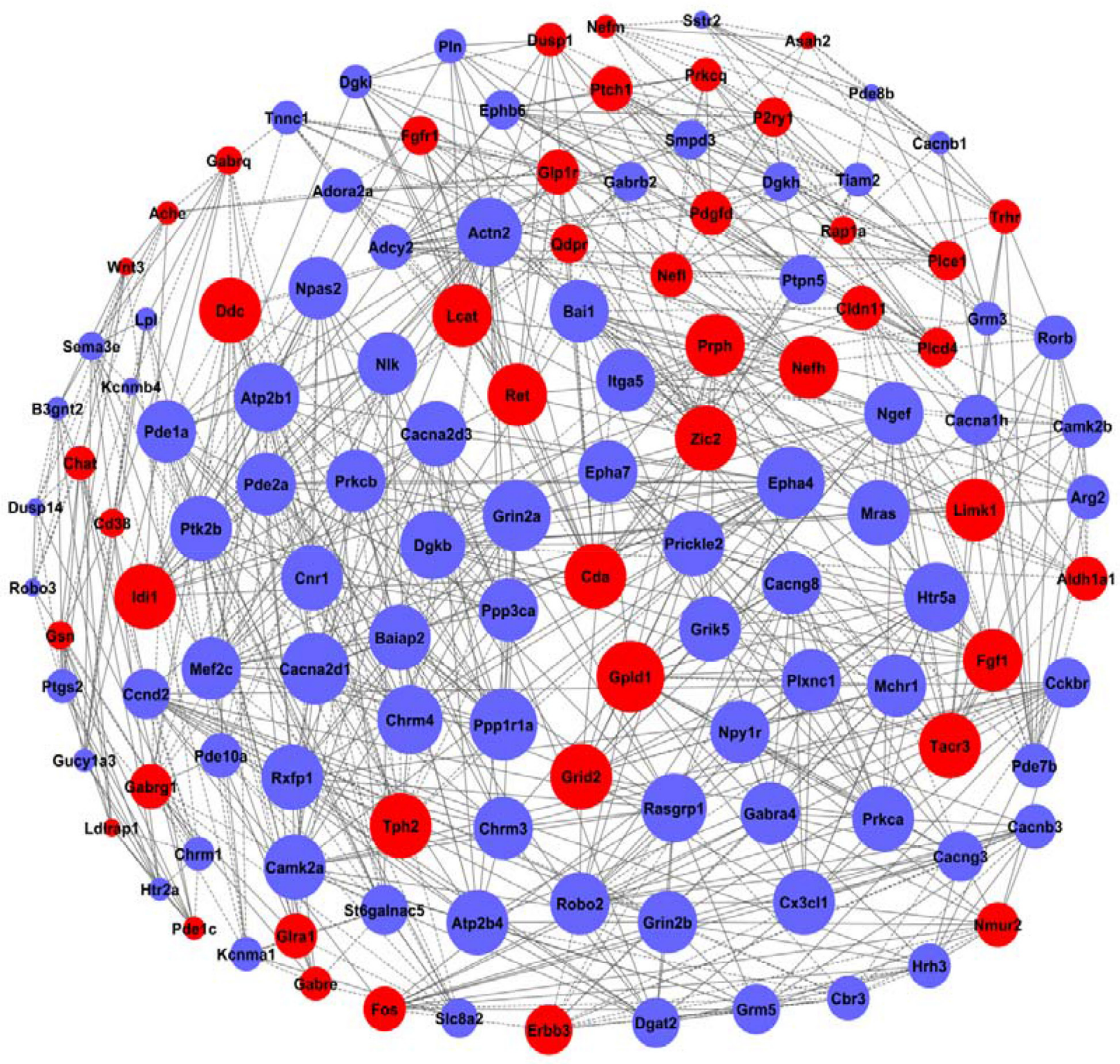

Figure 6: The co-expression network of genes formed from the HPC experimental group. The genes contained in significant GO terms were analyzed and identified by the gene co-expression network with the k-core algorithm. The node represents the gene, the red nodes mean the up-regulated genes, the blue nodes mean the down-regulated, and all the nodes were marked with the k-core values. Genes with higher k-core values are more centralized in the network and have a stronger capacity of modulating adjacent genes. The line represents the regulatory relationship, the solid line means the positive regulation and the dotted line means the negative regulation. 
the level of glutamate in the HPC brain markedly reduced, inferring that HPC could protect the cell from hypoxic damage via reducing calcium overload. This key process can be suppressed by blocking the NMDA receptor subtype and reducing glutamate level.

Glral mainly encoded the $\alpha_{1}$ subunit of a glycine receptor that consisted of three $\alpha$ subunits and two $\beta$ subunits [32]. The glycine receptor was a member of cys-loop family of ligand-gated ion channels, which was responsible for mediating the inhibitory effects of glycine. They widely distributed in central nervous system and were important inhibitory receptors. Glral was upregulated at least 47-fold in the HPC mice, the biggest fold change among the up-regulated genes. The GO analysis showed that the functions of Glral included the ion transport, synaptic transmission, neuropeptide signaling pathway, chloride transport, membrane potential and action potential. The pathway analysis indicated that Glral may play a role in neuroactive ligand-receptor interaction. The high levels of glycine could exert neuroprotective effects by activating the glycine receptor and increasing the NMDA subunit component [33]. The evidence suggested that glycine could protect cells from hypoxia damage via up-regulating the $\alpha_{1}$ subunit and inhibiting the activation of membrane voltage-dependent $\mathrm{Ca}^{2+}$ channels to block $\mathrm{Ca}^{2+}$ influx into the cell.

All eukaryotic cells require oxygen for oxidative phosphorylation to generate high-energy phosphates adenosine triphosphate (ATP). The energy-rich molecules are used to maintain the normal cellular functions such as proliferation, membrane transport and metbolic reactions [34]. Significant changes in the metabolic responses as a result of adaptation to hypoxia can be observed in the cells of HPC animals. More importantly, the metabolic rate depression is achieved by targeting and coordinating the rates of energy-producing pathways and energyutilizing functions, and reorganizing the priorities for ATP expenditure [35]. Currently, some novel biomarkers and metabolic pathways in HPC are being investigated using modern analytical technologies to obtain global omic profiles in the cell/organ of interests in our laboratory. The modern omics allow us to make major advances in understanding of how organisms adapt their metabolism to endure hypoxia. Especially, the "global view" is critical in showing both the breadth of cellular responses and commonalities of molecular mechanisms that underlie organismal adaptation to hypoxia. In previous work, we have seen some crucial changes in corresponding endogenous metabolites such as peptides, amino acids, sphingolipids, and spermidine, etc, and these metabolites had important roles in providing ATP and maintaining cell survival. Some of the metabolites had been identified with HPLC-HRMS and the standard compounds [8]. The functions and pathways of these metabolites need to further study.

The gene expression profiles in brain of HPC mice were generated and integrated using a multi-step bioinformatics strategy to determine the HPC-related hub genes, pathways, network and biological processes. Our results indicated that the expression profiles of the key genes in the HPC mice were markedly different from that in the sham-HPC mice. Several critical hub genes, as the key members of significant pathways or gene networks, were identified by this comprehensive analysis.

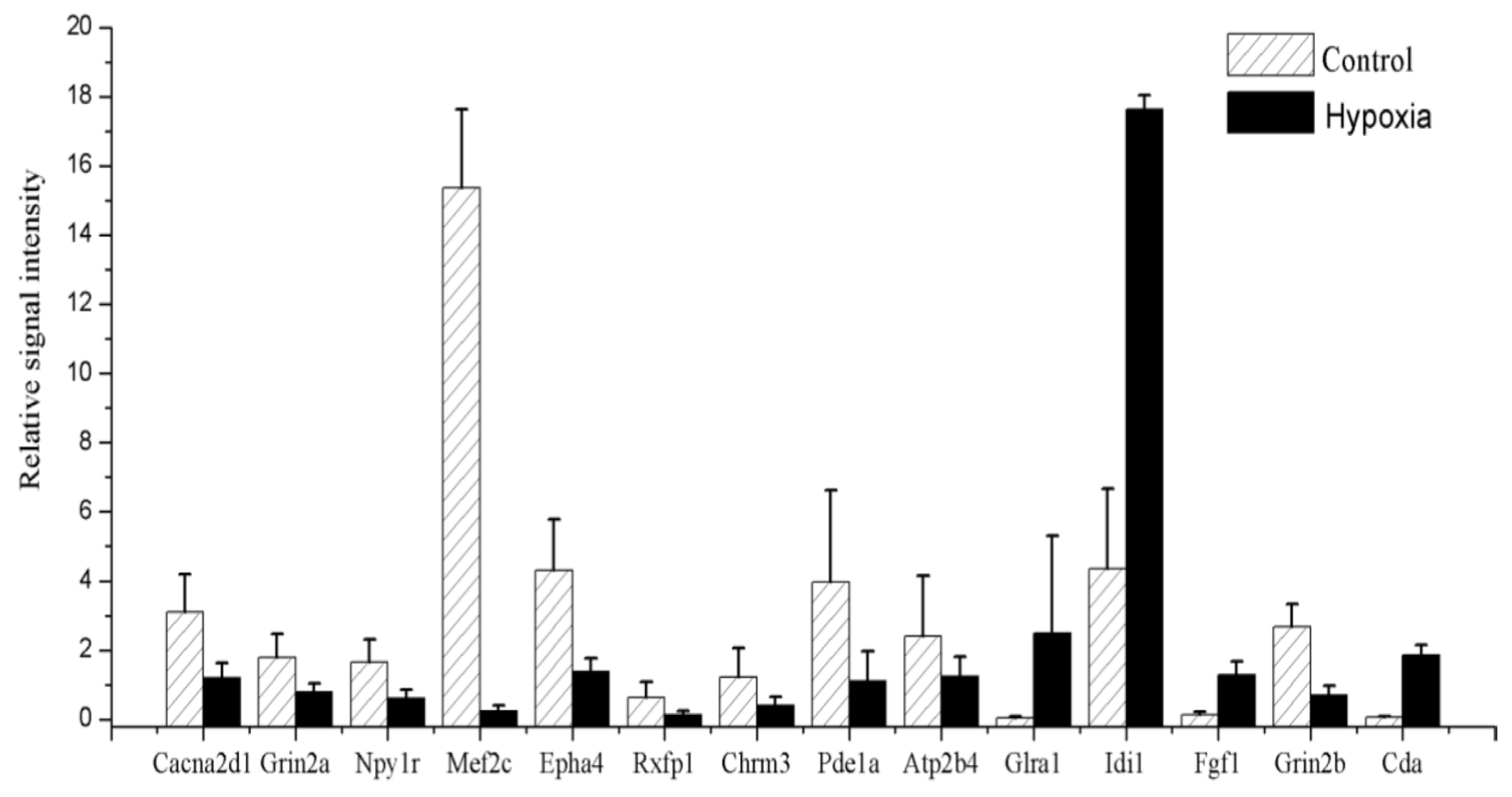

Gene name

Figure 7: The relative signal intensity of genes between the control and HPC group. 
Combined the results of pathway network and gene coexpression network, (see Supplementary Table 3 and Supplementary Table 4), we defined Plcb1, Cacna2d1, Atp2b4, Grin2a, Grin2b and Glral as the main hub genes tightly related with HPC. The results showed that the upregulated genes were mainly involved in the ion transport, neurotransmitter transport, synapse transduction, signal conduction, cranial nerve development and neuropeptide signal path, while the down-regulated genes were mainly involved in the calcium ion transport, nerve phylogenies, brain development, neuron migration and neuron differentiation. During the HPC, the cells may use several molecular mechanisms to change the metabolic pathways, respiratory chain and electron transport for decreasing the energy requirement and intracellular $\mathrm{Ca}^{2+}$ level to prevent calcium overload and protect the organism from hypoxia damage. To summarize, we firstly found that the global gene expression profiles in mice brain tissues were significantly different between the HPC and the shamHPC control mice. The findings of the hub genes and integrated gene networks may provide pivotal and useful information for exploring the molecular mechanisms in HPC, cerebral ischemic injury and neuroprotection.

\section{MATERIALS AND METHODS}

\section{Drug and reagents}

RNA extract kit included Qiagen Rneasy Mini Kit (number 217004, Qiagen Co., Ltd., Germany), Qiagen Rnase-free Dnase I (number 79254, Qiagen Co., Ltd., Germany), Ambion WT Expression Kit (Ambion Co., Ltd., USA), Affymetrix gragmentation and labelling kit (Gene Chip 2 WT Terminal Labeling Kit and Controls Kit 30 times, Affymetrix Co., Ltd., USA). Affymetrix reagents were the eneChip2 Hybridization, Wash and Stain Kit (Affymetrix Co., Ltd., USA).

\section{Animals and HPC experiments}

Adult male Imprinting Control Region (ICR) mice, body weight 18-20 g, were obtained from the Laboratory Animals Center of Capital Medical University. The experiments were carried out in accordance with the current guidelines for the care of laboratory animals and ethical guidelines for investigations of experiments in conscious animals [36, 37]. In addition, the experimental protocols employed were approved by the Animal Care and Use Committee of Capital Medical University and consistent with the NIH Guide for the Care and Use of Laboratory Animals (NIH Publications No. 80-23). The six mice were allocated randomly to the HPC group and the sham-HPC group as the control. A "power test" based on the standard deviation of the mean have been carried out to determine the number of animals required. All mice were bred in isolated cages.

Acute repetitive hypoxia models were constructed at room temperature $\left(20 \pm 1^{\circ} \mathrm{C}\right)$, and used to identify the main differentially expressed genes related to HPC. The acute repetitive hypoxia mice were treated as reported previously [5-8, 38]. Briefly, a mouse was placed in a $125 \mathrm{ml}$ airtight jar containing air and the bottom of jar with $\mathrm{Ca}(\mathrm{OH})_{2}$ to absorb $\mathrm{CO}_{2}$. The jar was immediately sealed with a rubber stopper and smeared with Vaseline. Simultaneously, the tolerance time and behavior of the mouse were observed. The mouse was taken out of the jar as soon as the asthmoid respiration just appeared. This is the first time of hypoxic preconditioning treatment. After ten minutes recovery under air condition, the mouse was moved to another new jar with same volume fresh air and the jar was hermetically sealed with rubber plug immediately, and to duplicate a progressive hypoxia environment. The control mice placed in open jars for the same amount of time were used as the normoxic shamHPC control group. These mice had just transferred to another open jar with same volume fresh air, but did not be sealed with rubber plug. The procedure was performed repeated six times (H6) for the experimental HPC mice and sham-HPC control mice [7]. After the experiment the animals were decapitated, and their whole brain tissues were collected on ice and saved in liquid nitrogen for use.

\section{Microarray experiment}

The procedures of microarray experiments mainly included: isolation and validation of the total RNA from the mouse brain, the reverse transcription and in vitro transcription of RNA (i.e. the first and second strand synthesis of first-cDNA, synthesis and purification of cRNA, synthesis and purification of 2nd-cDNA), and then label and hybridization of the samples (including gragmentation of 2nd-cDNA, label of gragmentated $2^{\text {nd }}$ cDNA, chip hybridization, and scrubbing and scanning of array) [39-41].

For the Affymetrix microarray profiling, total RNA was isolated with TRIzol reagent (Invitrogen, Canada) from whole brain and purified using a RNeasy Mini Kit (Qiagen, German), including a DNase digestion treatment. The RNA concentration was determined by absorbance at $260 \mathrm{~nm}$. The quality control standards of A260/A280 were 1.8-2.1 using the Nano Drop 2000 (Thermo, America). The cDNA from the repeated six times HPC group and the sham-HPC control group was hybridized to Mouse Gene 1.0 ST GeneChip arrays (Affymetrix, USA) according to the manufacturer's instructions. The Affymetrix Expression Console software (version 1.2.1) was used for microarray analysis. Raw data (CEL files) were normalized at transcription level using the robust multi-average method (RMA workflow). The median summarization of transcript expression levels was calculated. The gene-level data were then filtered to include only the probe sets in the 'core' meta-probe list, which represents the RefSeq genes [40]. 
For each sample, three biological replicates were performed. The Two ClassDif was used to screen and analyze the differentially expressed genes in these samples, which was the $t$-test method via an adjustment of model for random variance. This method effectively improves the accuracy of characteristic screening and reduce the false positive rate. All arrays were washed, stained, and read by a GeneChip Scanner 3000 (Affymetrix). The fluorescence signal was excited at 570 $\mathrm{nm}$, and the data were collected on a confocal scanner at $3 \mathrm{~lm}$ resolution. The data were analyzed by the GeneChip Operating Software 1.4.

\section{Differential gene analysis}

Significant differential genes between the experimental group and control group were screened using the relative variance method (RVM) from the $t$-test [41]. The threshold of truly significant genes was taken to be $p$-value $<0.05$ and the false discovery rate $(\mathrm{FDR})<0.05$.

\section{Gene ontology and pathway analysis}

Gene Ontology (GO) analysis was applied to analyze the main functions of the differentially expressed genes [42]. GO annotations are the main functional classification used by the National Center for Biotechnology Information (NCBI). A total of 1175 genes in the significant differential gene group were classified and analyzed based on their GO functional annotations. The GO terms assigned to these genes were obtained and examined using the Fisher's exact test and chi-square $\left(\chi^{2}\right)$ test to calculate the level of significance. The threshold was taken to be $p$-value $<0.05$ and the FDR value $<0.05$. For the functions in significant category, the enrichment $\left(R_{\mathrm{e}}\right)$ was calculated as $R_{\mathrm{e}}=$ $\left(\mathrm{n}_{\mathrm{f}} / \mathrm{n}\right) /\left(\mathrm{N}_{\mathrm{f}} / \mathrm{N}\right)$, where $\mathrm{n}_{\mathrm{f}}$ is the number of differential genes within a GO category of interest, $\mathrm{n}$ is the total number of genes in the category, $\mathrm{N}_{\mathrm{f}}$ is the number of differential genes in the entire microarray, and $\mathrm{N}$ is the total number of genes in the microarray.

Pathway analysis of significant differential genes was based on the KEGG (Kyoto Encyclopedia of Genes and Genomes), BioCarta and Reactome databases [42]. The Fisher's exact test and $\chi^{2}$ test were used to classify the enrichment of pathway categories and the threshold of significance was defined by $p$-value $<0.05)$ and the FDR value $<0.05$. For the pathways in the significant category, the enrichment $\left(R_{\mathrm{e}}\right)$ was calculated as $R_{\mathrm{e}}=(\mathrm{i} / \mathrm{m}) /(\mathrm{k} / \mathrm{N})$, where the $\mathrm{i}$ is the number of differential genes within a pathway category of interest, $\mathrm{m}$ is the total number of genes in that category, $\mathrm{k}$ is the number of differential genes in the entire microarray, and $\mathrm{N}$ is the total number of genes detected in the microarray.

The PathNet program was constructed based on the interactions among the pathways of KEGG database to find the interactions among significant pathways directly and systemically [12]. Here, we used the PathNet $\mathrm{R}$ package to build an interaction network of significant pathways from the differential expression genes to identify differential networks that might help explain why certain pathways were activated in HPC.

\section{Gene co-expression network analysis}

The signal intensities of differentially expressed genes were used to build the gene co-expression networks [43]. Pearson's correlations $(R)$ for each pair of genes were calculated and used to select the significant correlation gene pairs. A gene-gene interaction network was established according to the correlations between the genes. The network nodes represent the genes, and the edges between the genes indicate the interaction between these genes. All the nodes were marked with degrees, defined as the number of links that one node with the all the other nodes in the network. The genes with the higher degrees occupied more of the central positions in the network and had a stronger capacity to modulate adjacent genes than the genes with the lower degrees. In addition, the k-core model was applied to describe the characteristics of the network including the centrality of genes within the network and the complexity of the sub-networks. Based on the relationships between the genes, they were divided into several sub-networks and marked red (upregulated) or blue (down-regulated).

\section{RT-PCR confirmation of differentially expressed genes}

Real-time RT-PCR was conducted to confirm the differential expression of 14 selected key genes, namely, Cacna2d1, Grin2a, Npy1r, Mef2c, Epha4, Rxfp1, Chrm3, Pdela, Atp2b4, Glra1, Idi1, Fgf, Grin2b and $C d a$. Total RNA was obtained from mice exposed to hypoxia conditions that were the same as those used in the microarray assay [44, 45]. Real-time RT-PCR was conducted in $20 \mu \mathrm{l}$ reaction mixtures, including $10 \mu$ Power SYBR Green PCR Master Mix (Applied Biosystems), $1 \mu$ l primers, $1 \mu$ template cDNA, and 8 $\mu$ nuclease-free water. The cycling program consisted of a single cycle of $5 \mathrm{~min}$ at $95^{\circ} \mathrm{C}$, followed by 40 cycles of $15 \mathrm{~s}$ at $95^{\circ} \mathrm{C}$, and $1 \mathrm{~min}$ at $60^{\circ} \mathrm{C}$ (see Table 3 ). The optimized $2^{-\Delta \Delta \mathrm{Ct}}$ method was used to calculate the relative gene expression. Cacna2dl was used as the internal control gene to normalize the amount of RNA added to the PCR reactions [15].

\section{ACKNOWLEDGMENTS}

We thank the Genminix Informativs Ltd., Co for the experiment advice and technical assistance in gene 
Table 3: The primer sequences for RT-PCR

\begin{tabular}{|c|c|c|c|}
\hline Gene symbol & Direction & Primer sequence (5'-3') & Product length (bp) \\
\hline \multirow[t]{2}{*}{ Cacna2d1 } & Forward & AGTTTATCCCAAAGAGGCCG & 149 \\
\hline & Reverse & TTCCAGATTCATACGCACCAG & \\
\hline \multirow[t]{2}{*}{ Grin2a } & Forward & TGGTGATCGTGCTGAATAAGG & 147 \\
\hline & Reverse & AGGTGACAATGCTGAGGTG & \\
\hline \multirow[t]{2}{*}{ Npylr } & Forward & GCCCACTCTGCTTTATATTCATATG & 108 \\
\hline & Reverse & ATTCGCTTGGTCTCACTGG & \\
\hline \multirow[t]{2}{*}{ Mef2c } & Forward & CCAGATCTCCGCGTTCTTATC & 149 \\
\hline & Reverse & ССТСССАТТССТТGТССТG & \\
\hline \multirow[t]{2}{*}{ Epha4 } & Forward & TCGTTATGTGGGAAGTGATGTC & 133 \\
\hline & Reverse & AACTGATGGAGGGCAATGG & \\
\hline \multirow[t]{2}{*}{ Rxfp1 } & Forward & TGTGCTGGATTCCCATCTTC & 148 \\
\hline & Reverse & AAAGGTCTAGTGGTCAACGTG & \\
\hline \multirow[t]{2}{*}{ Chrm3 } & Forward & TCGGTAGAGCGGACTGG & 148 \\
\hline & Reverse & TTCACTCAATCCACAGTCCAC & \\
\hline \multirow[t]{2}{*}{ Pdela } & Forward & TGCTATTCTGTACAACGACCG & 148 \\
\hline & Reverse & GACCATTTCAATCACTAAGTTCCG & \\
\hline \multirow[t]{2}{*}{ Atp2b4 } & Forward & GGATTGGAGAACTTTTGTGGG & 145 \\
\hline & Reverse & ATCTCGGCAAGGTCAATCTC & \\
\hline \multirow[t]{2}{*}{ Glral } & Forward & GGAAGAGAAAGACCTGAGATACTG & 144 \\
\hline & Reverse & GACAGGATGACGATGAGCAG & \\
\hline \multirow[t]{2}{*}{ Idil } & Forward & ATTGGTGTGAAGCGAGCA & 133 \\
\hline & Reverse & CACCCCAGATACCATCAGATTG & \\
\hline \multirow[t]{2}{*}{ Fgf1 } & Forward & TGGGACAAGGGACAGGAG & 150 \\
\hline & Reverse & TCCTCATTTGGTGTCTGCG & \\
\hline \multirow[t]{2}{*}{ Grin $2 b$} & Forward & AAGGAGAGGAAGTGGGAGAG & 128 \\
\hline & Reverse & AAGGTAACGATGCTCAGATGG & \\
\hline \multirow[t]{2}{*}{$\mathrm{Cda}$} & Forward & CTGCCGACAAGTCATGAGAG & 122 \\
\hline & Reverse & GGTCTTCAGGTCCAAACGAG & \\
\hline \multirow[t]{2}{*}{$\beta$-actin } & Forward & АCСТTCTACAATGAGCTGCG & 146 \\
\hline & Reverse & CTGGATGGCTACGTACATGG & \\
\hline
\end{tabular}

bioinformatics analysis. We thank Dr. Beikang Ge for revising our article.

\section{CONFLICTS OF INTEREST}

The authors have no conflicts of interest to declare.

\section{FUNDING}

This work was supported by the Program of National Foundation of Natural Sciences of China (81173121, 81573683 \& 81773803), the Projects for Academic Human Resources Development in Institutions of High Learning under the Jurisdicrion of Beijing Municipality of China (PHR201007111) and Beijing Laboratory for Biomedical Detection Technology and Instrument (PXM2014-014226000021).

\section{REFERENCES}

1. Lu GW, Cui XY, Zhao BM. Alterations of oxygen consumption and energy metabolism during repetitive exposure of mice to hypoxia. Neurochem Res. 1999; 24:625-628.

2. Lu GW, Ding D, Shi M. Acute adaptation of mice to hypoxic hypoxia. Biol Sig Recept. 1999; 8:247-255.

3. Lin WC, Coppi MV, Lovley DR. Geobacter sulfurreducens can grow with oxygen as a terminal electron acceptor. Appl Environ Microbiol. 2004; 70:2525-2528.

4. Lu GW, Yu S, Li RH, Cui XY, Gao CY. Hypoxic preconditioning: a novel intrinsic cytoprotective strategy. Mol Neurobiol. 2005; 31:255-271.

5. Wang MM, Wang LJ, Chen Y, Li XR, Lv GW, Xue M. Establishment of the prediction model of tolerance time of mice and rats exposed to hypoxia. Chin J Comp Med. 2008; 18:21-23. 
6. Shao G, Lu GW. Hypoxic preconditioning in an autohypoxic animal model. Neurosci Bul. 2012; 28:316-320.

7. Cui C, Zhou T, Li J, Wang H, Li X, Xiong J, Xu P, Xue M. Proteomic analysis of the mouse brain after repetitive exposure to hypoxia. Chem Biol Interact. 2015; 236:57-66.

8. Zhou T, Wang M, Cheng H, Cui C, Su S, Xu P, Xue M. UPLC-HRMS based metabolomics reveals the sphingolipids with long fatty chains and olefinic bonds up-regulated in metabolic pathway for hypoxia preconditioning. Chem Biol Interact. 2015; 242:145-152.

9. Vu Manh TP, Dalod M. Characterization of dendritic cell subsets through gene expression analysis. Methods Mol Biol. 2016; 1423:211-243.

10. Chen F, Zhu HH, Zhou LF, Li J, Zhao LY, Wu SS, Wang J, Liu W, Chen Z. Gene related to the very early stage of ConA-induced fulminant hepatitis: a gene-chip-based study in a mouse model. BMC Genomics. 2010; 11:240-252.

11. Cline MS, Smoot M, Cerami E, Kuchinsky A, Landys N, Workman C, Christmas R, Avila-Campilo I, Creech M, Gross B, Hanspers K, Isserlin R, Kelley R, et al. Integration of biological networks and gene expression data using Cytoscape. Nat Protoc. 2007; 2:2366-82.

12. Pandey AK, Munjal N, Datta M. Gene expression profiling and network analysis reveals lipid and steroid metabolism to be the most favored by tnfo in hepg2 cells. PloS One. 2010; 5, e9063.

13. Stokić D, Wick N, Biely C, Gurnhofer E, Thurner S. Statistically consistent identification of differentially expressed genes in DNA chip data over the whole expression range: relative variance method. Appl Bioinformatics. 2006; 5:277-284.

14. West CM, Elliott RM, Burnet NG. The genomics revolution and radiotherapy. Clinical Oncol. 2007; 19:470-480.

15. Ashburner M, Ball CA, Blake JA, Botstein D, Butler H, Cherry JM, Davis AP, Dolinski K, Dwight SS, Eppig JT, Harris MA, Hill DP, Issel-Tarver L, et al, and The Gene Ontology Consortium. tool for the unification of biology. Nat Genet. 2000; 25:25-29.

16. Jones DR, Baričević I. Inositol: A building block for both signal transduction and for making life or death decisions. Acta Physiol Pharmacol Serbica. 2006; 42:61-76.

17. Karlsson M, Mandl M, Keyse SM. Spatio-temporal regulation of mitogen-activated protein kinase (MAPK) signalling by protein phosphatases. Biochem Society Transact. 2006; 34:842-845.

18. Zhang B, Horvath S. A general framework for weighted gene co-expression network analysis. Stat Appl Genet Mol Biol. 2005; 4:e17.

19. Presson AP, Sobel EM, Papp JC, Suarez CJ, Whistler T, Rajeevan MS, Vernon SD, Horvath S. Integrated weighted gene co-expression network analysis with an application to chronic fatigue syndrome. BMC Syst Biol. 2008; 2:95-99.

20. Serkova NJ, Reisdorph NA, Tissot van Patot MC. Metabolic markers of hypoxia: systems biology application in biomedicine. Toxicol Mech Methods. 2008; 18:81-95.
21. Heiner M, Sriram K. Structural analysis to determine the core of hypoxia response network. PloS One. 2010; 5:e8600.

22. von Mering C, Bork P. Teamed up for transcription. Nature. 2002; 417:797-798.

23. Dhaeseleer P, Liang S, Somogyi R. Genetic network inference: from co-expression clustering to reverse engineering. Bioinformatics. 2000; 16:707-726.

24. Bu X, Zhang N, Yang X, Liu Y, Du J, Liang J, Xu Q, Li

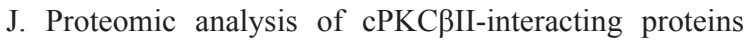
involved in HPC-induced neuroprotection against cerebral ischemia of mice. J Neurochem. 2011; 117:346-356.

25. Waugh MG. Chromosomal instability and phosphoinositide pathway gene signatures in glioblastoma multiforme. Mol Neurobiol. 2016; 53:621-30.

26. Andrade A, Sandoval A, González-Ramírez R, Lipscombe D, Campbell KP, Felix R. The alpha(2)delta subunit augments functional expression and modifies the pharmacology of Ca(V)1.3 L-type channels. Cell Calcium. 2009; 46:282-292.

27. Hou GY, Yuan ZR, Gao X, Li JY, Gao HJ, Chen JB, Xu SZ. Genetic polymorphisms of the Cacna2d1 gene and their association with carcass and meat quality traits in cattle. Biochem Genetics. 2010; 48:751-759.

28. Mittelstadt PR, Salvador JM, Fornace AJ, Ashwell JD. Activating p38 MAPK: new tricks for an old kinase. Cell Cycle. 2005; 4:1189-1192.

29. Geyik E, Igci YZ, Pala E, Suner A, Borazan E, Bozgeyik I, Bayraktar E, Bayraktar R, Ergun S, Cakmak EA, Gokalp A, Arslan A. Investigation of the association between atp2b4 and atp5b genes with colorectal cancer. Gene. 2014; 540:178-182.

30. Dimroth $\mathrm{P}$, von Ballmoos C, Meier T. Catalytic and mechanical cycles in F-ATP synthases. Fourth in the Cycles Review Series. EMBO Rep. 2006; 7:276-82.

31. Kim KT, Kim J, Han YJ, Kim JH, Lee JS, Chung JH. Assessment of NMDA receptor genes (grin2a, grin2b and grin2c) as candidate genes in the development of degenerative lumbar scoliosis. Exp Ther Med. 2013; 5:977-981.

32. Villmann C, Oertel J, Ma-Högemeier ZL, Hollmann M, Sprengel R, Becker K, Breitinger HG, Becker CM. Functional complementation of Glra1(spd-ot), a glycine receptor subunit mutant, by independently expressed C-terminal domains. J Neurosci. 2009; 29:2440-2452.

33. Yao W, Ji F, Chen Z, Zhang N, Ren SQ, Zhang XY, Liu SY, $\mathrm{Lu}$ W. Glycine exerts dual roles in ischemic injury through distinct mechanisms. Stroke. 2012; 43:2212-2220.

34. Lendahl U, Lee KL, Yang H, Poellinger L. Generating specificity and diversity in the transcriptional response to hypoxia. Nat Rev Genet. 2009; 10:821-832.

35. Storey KB, Storey JM. Metabolic rate depression in animals: transcriptional and translational controls. Biol Rev Camb Philos Soc. 2004; 79:207-33.

36. Zimmermann M. Ethical guidelines for investigations of experimental pain in conscious animals. Pain. 1983; 16:109-10. 
37. Li JF, Niu C, Han S, Zu P, Li H, Xu Q, Fang L. Identification of protein kinase $\mathrm{C}$ isoforms involved in cerebral hypoxic preconditioning of mice. Brain Res. 2005; 1060:62-72.

38. Zhang N, Yin Y, Han S, Jiang J, Yang W, Bu X, Li J. Hypoxic preconditioning induced neuroprotection against cerebral ischemic injuries and its $\mathrm{cPKC} \gamma$-mediated molecular mechanism. Neurochem Int. 2011; 58:684-692.

39. Wright GW, Simon RM. A random variance model for detection of differential gene expression in small microarray experiments. Bioinformatics. 2003; 19:2448-2455.

40. Clarke R, Ressom HW, Wang A, Xuan J, Liu MC, Gehan EA, Wang Y. The properties of high-dimensional data spaces: implications for exploring gene and protein expression data. Nat Rev Cancer. 2008; 8:37-49.

41. Dupuy D, Bertin N, Hidalgo CA, Venkatesan K, Tu D, Lee D, Rosenberg J, Svrzikapa N, Blanc A, Carnec A, Carvunis AR, Pulak R, Shingles J, et al. Genome-scale analysis of in vivo spatiotemporal promoter activity in Caenorhabditis elegans. Nat Biotechnol. 2007; 25:663-668.

42. Gene Ontology Consortium. The Gene Ontology (GO) project in 2006. Nucleic Acids Res. 2006; 34:D322-26.

43. Livak KJ, Schmittgen TD. Analysis of relative gene expression data using real-time quantitative PCR and the 2(T) (-Delta Delta C) method. Methods. 2001; 25:402-408.

44. Zhang JD, Wiemann S. KEGG graph: a graph approach to KEGG pathway in $\mathrm{R}$ and bioconductor. Bioinformatics. 2009; 25:1470-1471.

45. Ryan JC, Morey JS, Bottein MY, Ramsdell JS, Van Dolah FM. Gene expression profiling in brain of mice exposed to the marine neurotoxin ciguatoxin reveals an acute antiinflammatory, neuroprotective response. BMC Neurosci. 2010; 11:107-114. 